\title{
Impact Analysis of Headway Distributions on Single-Lane Roundabout Entry Capacity
}

\author{
Liang Ren ${ }^{1}$ and Xiaobo $\mathrm{Qu}^{2}$ \\ ${ }^{1} \mathrm{PhD}$ Candidate, Griffith School of Engineering, Griffith University, Room 2.24, G39, Griffith School of Engineering, \\ Griffith University, Gold Coast, 4222 Australia, E-mail: l.ren@griffith.edu.au \\ ${ }^{2}$ Senior Lecturer, Griffith School of Engineering, Griffith University, Room 1.17, G09, Griffith School of Engineering, \\ Griffith University, Gold Coast, 4222 Australia, E-mail: x.qu@griffith.edu.au (corresponding author).
}

Engineering Management

Best Paper of EPPM2015 Conference

Received November 18, 2015; received revision December 13, 2015; accepted December 18, 2015

Available online January 16, 2016

\begin{abstract}
Based on observed data, this paper evaluates the performance of capacity estimation for single-lane roundabouts using the Highway Capacity Manual (HCM) 2000 model. In this study, the HCM 2000 model is indicated to be over- or under estimate roundabout entry capacity. This is because the HCM 2000 model estimates capacity using an unfit assumption of headway distribution type. According to this finding, we propose a modified model to adjust the HCM 2000 model. Based on a comparison study, the modified model produces smaller relative error (0.92) and rootmean-square deviation (12.79) than the HCM 2000 model (4.66 and 48.17, respectively). It is believe that the modified HCM 2000 model outperforms the HCM 2000 model.
\end{abstract}

Keywords: Headway distribution type analysis, modified HCM 2000 model, roundabout entry capacity.

\section{Introduction}

A roundabout is a type of circular intersection with one or more marked lanes in which road traffic is slowed and flows almost continuously in one direction around a central island to several exits onto the various intersecting roads (Hellinga and Sindi, 2012; Ko, 2012). The early roundabouts are proposed a gyratory traffic scheme (i.e. one way circulation around a central island) (Qiu and Yin, 2011; Lee, 2015). Along with increase of traffic volume modern roundabouts are designed and established to satisfy higher requirements of safety, capacity and fluidity (Turner et al., 2011). Modern roundabouts have successfully implemented in Europe, Australia and the United States. Currently, there are over 1000 roundabouts in Australia and over 1600 roundabouts in the United States (Kittleson and Associates, 2011). Nowadays, roundabouts have been an increasingly popular intersection type, especially in less populous suburbs. In general, roundabouts substantially reduce queue and delay under low volume conditions as vehicles are not required to perform a complete stop (Munawar and Haryanto, 2010; Yap et al., 2015; Qu et al., 2014). Roundabouts allow Uturn within the normal flow of traffic, which are often difficult to implement at other forms of junction (Flannery, 2011). Further, roundabouts provide higher safety than signal controlled junctions in terms of not only frequency but also severity of accidents. Fortuijn (2009) asserted that as the vehicles in a roundabout could drive along the same direction, the probability of crashes could be reduced thanks to the decrease of conflicting points. For instance, total crashes were reduced by $35 \%$ and injury crashes were reduced by $76 \%$ for roundabouts compared to other intersection types in the United States (Rodegerdts et al., 2010). Similar results have also been found in Australia, France, Germany, Netherlands and the United Kingdomcrash and injury reduction by $61 \%$ and $87 \%$ (Rodegerdts et al., 2010). Along with the wider use of roundabouts, the entry capacity is of more importance to transport agencies (Bared and Afshar, 2009; Wei and Grenard, 2011).

Various models have been developed to estimate the entry capacities of roundabouts (Bie et al., 2012; Diah et al., 2011; Wong, 1996). Highway Capacity Manual (HCM) 2000 model is the most widely-used analytical model based on the gap acceptance theory (TRB, 2000), mathematically,

$$
C_{2000}=v_{c} \times \frac{\exp \left(-v_{c} \tau_{c} / 3600\right)}{1-\exp \left(-v_{c} \tau_{f} / 3600\right)}
$$

where $C_{2000}$ is the entry capacity of an arm (veh/hr); $v_{c}$ is the conflicting circulating flow (veh/hr); $\tau_{c}$ and $\tau_{f}$ are critical gap and follow-up time (sec), respectively.

In the above-mentioned model, the entry capacity is calculated as a function of conflicting circulating flow, critical gap, and follow-up time (Sarker and Baylot, 2012; Al-Ghandour et al., 2011; Mauro and Branco, 2010). Additionally, the HCM 2000 model assumes that the circulating headways follow an exponential distribution (Lochran et al., 2014; Yousif et al., 2013; Pinna and Piras, 2011; Polus et al., 2003; Wei and Grenard, 2012). 
However, some studies indicated that the HCM 2000 model may under- or over-estimate roundabout capacity (Mereszczak et al., 2006), and a relative error does exist in the HCM 2000 model (Cowan, 1997). Based on our research, follow-up time is possible to be measured from field survey. Furthermore, as critical gap cannot be observed directly, many feasible methods have been developed for its estimation from observed rejected and accepted gaps, such as those of Siegloch (1973), Raff (1950), Harder (1968) and Wu (2012). Accordingly, we conjecture that the relative error can be explained by an unrealistic assumption of headway distribution type. Hence, we intend to analyse impact of headway distribution type. To this end, this study begins with confirming a best fitted distribution type that circulating headways follow. Based on the accrual distribution types, we are able to modify the HCM 2000. In this study, we observed nine roundabouts (one hour per roundabout) to collect field survey data.

\section{Data Collection}

Based on field survey, nine roundabouts located in Gold Coast QLD, Australia are used to collect circulating headways, critical gaps and follow-up times at peak hour.

\subsection{Headways}

Headway is a time gap between two consecutive vehicles in circulating stream (Isebrand and Hallmark, 2012). As can be seen in Fig. 1, headways are counted as time difference between two consecutive vehicles passing the red line.

\subsection{Critical gap}

The critical gap is estimated using the distributions of gap acceptance and rejection data. The methods commonly used for estimating the critical gap include the graphical method (Flannery and Datta, 1997; Siegloch, 1973), the maximum likelihood method (Harders, 1968; Raff and Hart, 1950; Troutbeck, 1992) and the probability equilibrium method ( $\mathrm{Wu}, 2012)$. The three methods are used to estimate critical gaps in this study. Dahl and Lee (2012) explained that the graphical method determines the critical gap by using cumulative distributions of individual entry vehicle's accepted and rejected gaps. A gap is considered acceptable if the driver of the entering vehicle perceives that the gap is sufficiently long enough for them to enter the roundabout (as indicated by vehicle entry). Otherwise, the gap is rejected. The critical gap is then defined as the point of intersection between the two cumulative distribution curves (of the accepted gaps and rejected gaps) plotted on the same graph. An example of the calibration of the critical gap is shown in Fig. 2.

As can be seen in Fig. 2, in this roundabout, the critical gap is estimated as $4.61 \mathrm{sec}$ using the graphical method. In addition, the maximum likelihood method of estimating critical gap is based on the fact that a driver's critical gap is between the range of his largest rejected gap and his accepted gap (Troutbeck, 1992). A probabilistic distribution for the critical gap must be assumed. Troutbeck (1992) used a lognormal distribution for the critical gaps. The distribution is skewed to the right and has non-negative values, as would be expected in these circumstances.
The following notations are used for subsequent equations:

$y_{i}=$ the logarithm of the gap accepted by the ith driver.

$x_{i}=$ the logarithm of the largest gap rejected by the $i$ th driver. $x_{i}=0$ if no gap was rejected.

$\mu=$ mean of the distribution of the logarithms of the individual driver's critical gaps.

$\sigma^{2}=$ variance of the distribution of the logarithms of the individual driver's critical gaps.

$F()=$ cumulative distribution function for the normal distribution.

The maximum likelihood of a sample of $n$ drivers having an accepted gap and a largest rejected gap of ( $y_{i}$, $\left.x_{i}\right)$ is:

$$
\prod_{i=1}^{n}\left[F\left(y_{i}\right)-F\left(x_{i}\right)\right]
$$

The logarithm $(L)$ of the likelihood is then

$$
L=\sum_{i=1}^{n} \ln \left[F\left(y_{i}\right)-F\left(x_{i}\right)\right]
$$

Troutbeck (1992) further provide a closed form equation to estimate the mean critical gap $\left(t_{c}\right)$ based on Eqn.(3), represented by

$$
t_{c}=\exp \left(\mu+0.5 \sigma^{2}\right)
$$

The mean critical gap is estimated as $4.60 \mathrm{sec}$ using the maximum likelihood method in the same roundabout.

In the probability equilibrium method, the cumulative distribution functions (CDF) of the accepted and rejected gaps are represented as $F_{a}(t)$ and $F_{r}(t)$, respectively. Wu (2012) asserted that the observed probability that a gap of length $t$ is accepted is $1-F_{a}(t)$ and that it is "notaccepted" is $F_{a}(t)$. Additionally, the observed probability that a gap of length $t$ is rejected is $F_{r}(t)$ and that is "notrejected" is $1-F_{r}(t)$. It is also pointed out by Wu (2012) that $F_{r}(t) \neq 1-F_{a}(t)$ and $1-F_{r}(t) \neq F_{a}(t)$ because an accepted gap in the major stream may not be equal to the actual critical gap. In reality, the accepted gap is always larger than the actual critical gap.

Denote the CDF of the critical gaps to be estimated by $F_{t c}(t)$, then the probability $P_{r, t c}(t)$ that a gap of length $t$ in the major stream would be rejected is $F_{t c}(t)$, and the probability $P_{a, t c}(t)$ that it would be accepted is $1-F_{t c}(t)$.

Considering the observed probability of both acceptance and rejection, Wu (2012) has the probability equilibrium 
4 Ren, L. and Qu, X.

$\left\{\begin{array}{l}P_{r, t c}(t)=F_{r}(t) P_{r, t c}(t)+F_{a}(t) P_{a, t c}(t) \\ P_{a, t c}(t)=\left(1-F_{a}(t)\right) P_{r, t c}(t)+\left(1-F_{r}(t)\right) P_{a, t c}(t)\end{array}\right.$ form:

The Eqn.(5) can be rewritten in the following matrix $\left(\begin{array}{c}P_{r, t c}(t) \\ P_{a, t c}(t)\end{array}\right)=\left(\begin{array}{cc}F_{r}(t) & F_{a}(t) \\ 1-F_{r}(t) & 1-F_{a}(t)\end{array}\right)\left(\begin{array}{c}P_{r, t c}(t) \\ P_{a, t c}(t)\end{array}\right)$

That is exactly the description of the equilibrium state of the probabilities $P_{a, t c}(t)$ and $P_{r, t c}(t)$ as a Markov Chain. In this formulation

$$
\left(\begin{array}{l}
P_{r, t c}(t) \\
P_{a, t c}(t)
\end{array}\right)
$$

Is the state vector and

$$
\left(\begin{array}{cc}
F_{r}(t) & F_{a}(t) \\
1-F_{r}(t) & 1-F_{a}(t)
\end{array}\right)
$$

the transition matrix. The boundary condition $P_{a, t c}(t)+P_{r, t c}(t)=1$ holds.

With $P_{r, t c}(t)=F_{t c}(t)$ and $P_{a, t c}(t)=1-F_{t c}(t)$, Eqn.(6) yields

$\left(\begin{array}{c}F_{t c}(t) \\ 1-F_{t c}(t)\end{array}\right)=\left(\begin{array}{cc}F_{r}(t) & F_{a}(t) \\ 1-F_{r}(t) & 1-F_{a}(t)\end{array}\right)\left(\begin{array}{c}F_{t c}(t) \\ 1-F_{t c}(t)\end{array}\right)$

Solving Eqn. (7) yields the CDF $F_{t c}(t)$ of the critical
$F_{t c}(t)=\frac{F_{a}(t)}{F_{a}(t)+1-F_{r}(t)}=1-\frac{1-F_{r}(t)}{F_{a}(t)+1-F_{r}(t)}$

In this study the CDF of critical gap can be easily established once CDFs of accepted and rejected time gaps are obtained. We collected 167 accepted gaps and 401 rejected gaps which are used to calibrate CDFs for accepted and rejected. Meanwhile, according to Eqn. (8), the CDF of critical gap is established shown in Fig. 3.

$\mathrm{Wu}$ (2012) indicated that this distribution is only explicitly defined, from the point of view of all vehicles, between the overall minimum accepted gap $a_{\min }$ and the overall maximum rejected gap $r_{\max }$ with $a_{\min }<r_{\max }$. For $t_{c}<a_{\min }$ is $F_{t c}(t)=0$ and for $t_{c}>r_{\max }$ is $F_{t c}(t)=1$. In case of $a_{\min }>r_{\max }$ the mean critical gap can be approximately calculated as $t_{c}=\left(a_{\min }+r_{\max }\right) / 2$. The mean critical gap is estimated as 4.62sec using the probability equilibrium method. In this study we found that the three methods provide similar results. The critical gaps for all roundabouts range from $4.59 \mathrm{sec}$ to $4.82 \mathrm{sec}$.

\subsection{Follow-up time}

In this study, all follow-up times are measured from each roundabout. The follow-up time is then calibrated by taking a mean value of all measured follow-up times for each roundabout. They range between $2.35 \mathrm{sec}$ and 2.75 sec. gaps:

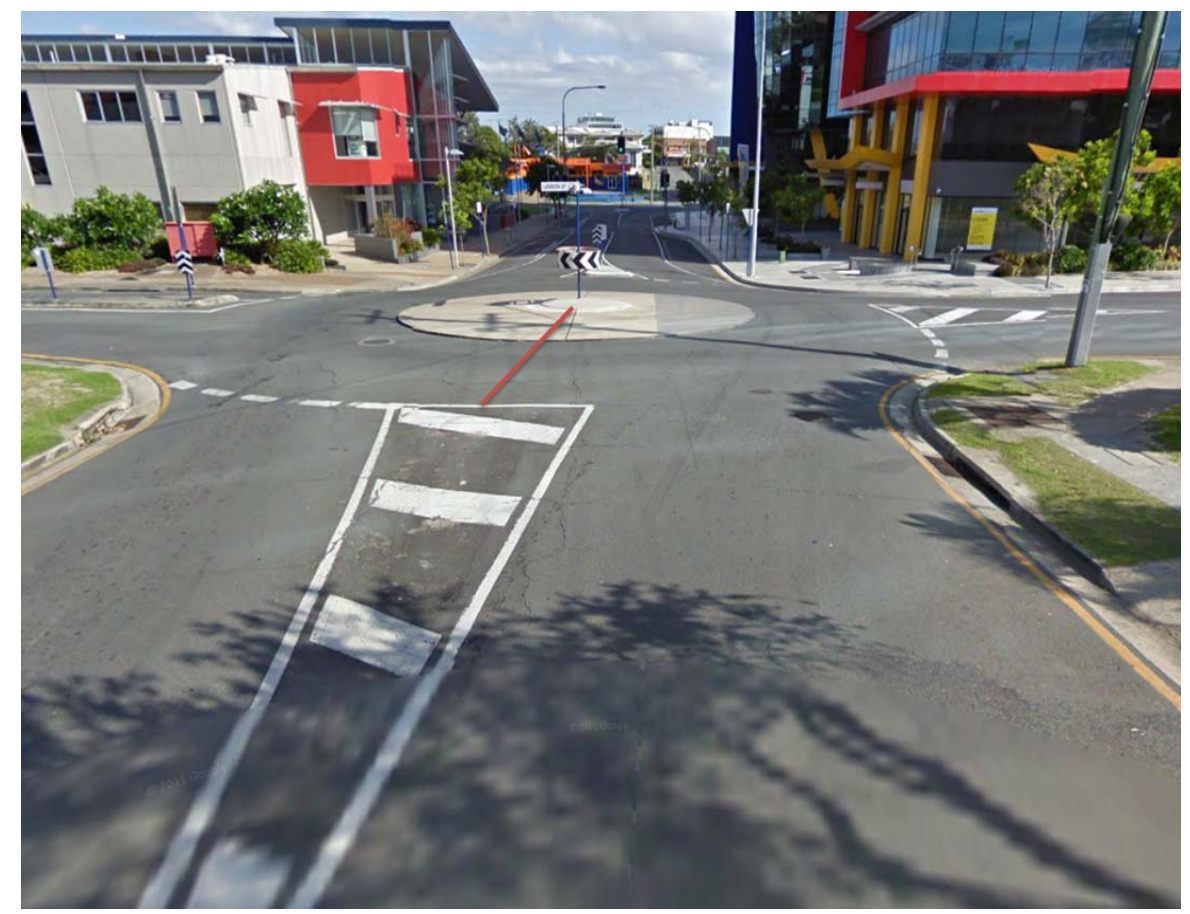

Fig. 1. An observed roundabout 
Impact Analysis of Headway Distributions on Single-Lane Roundabout Entry Capacity 5

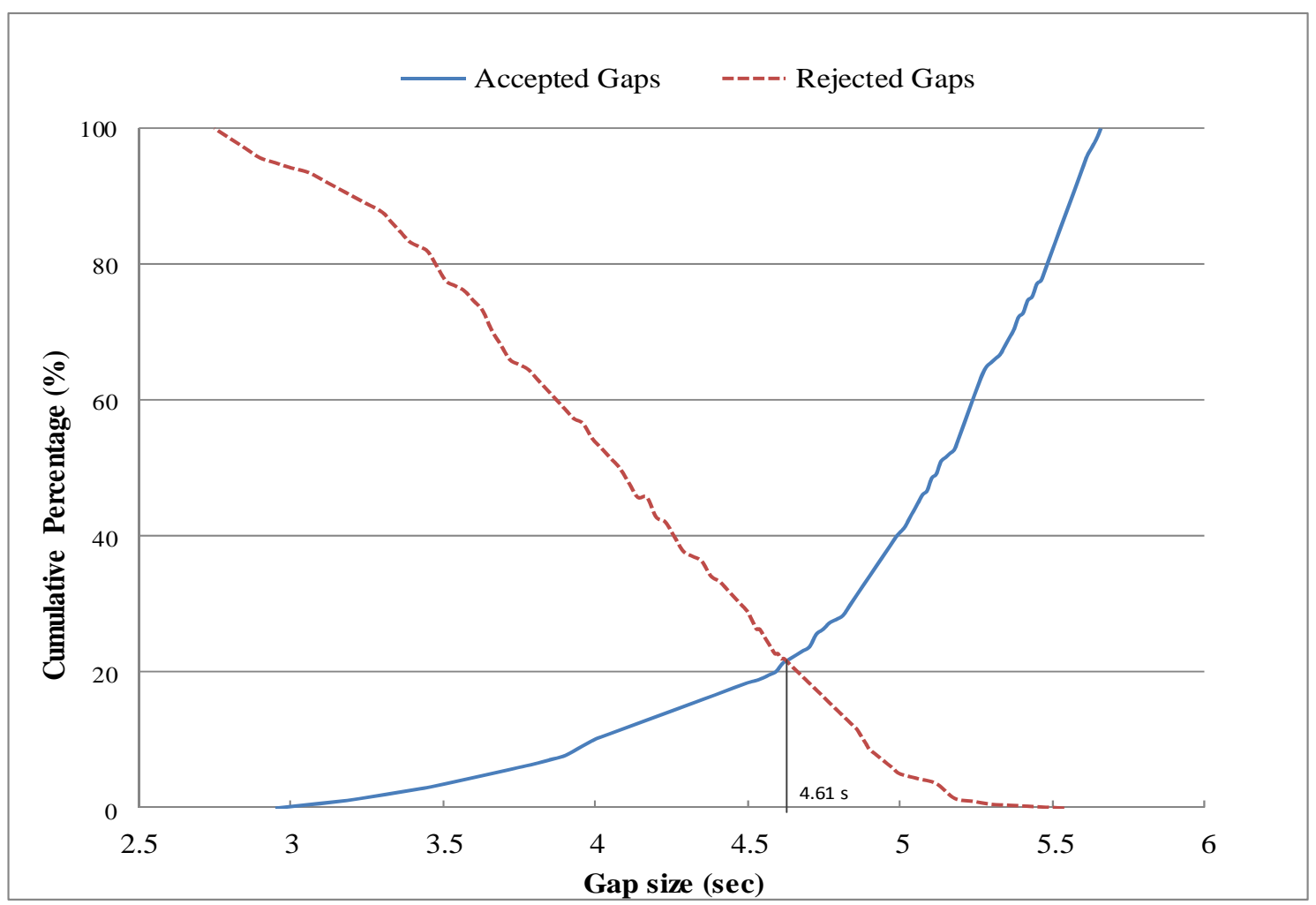

Fig. 2. Calibration of critical gap using the graphical method

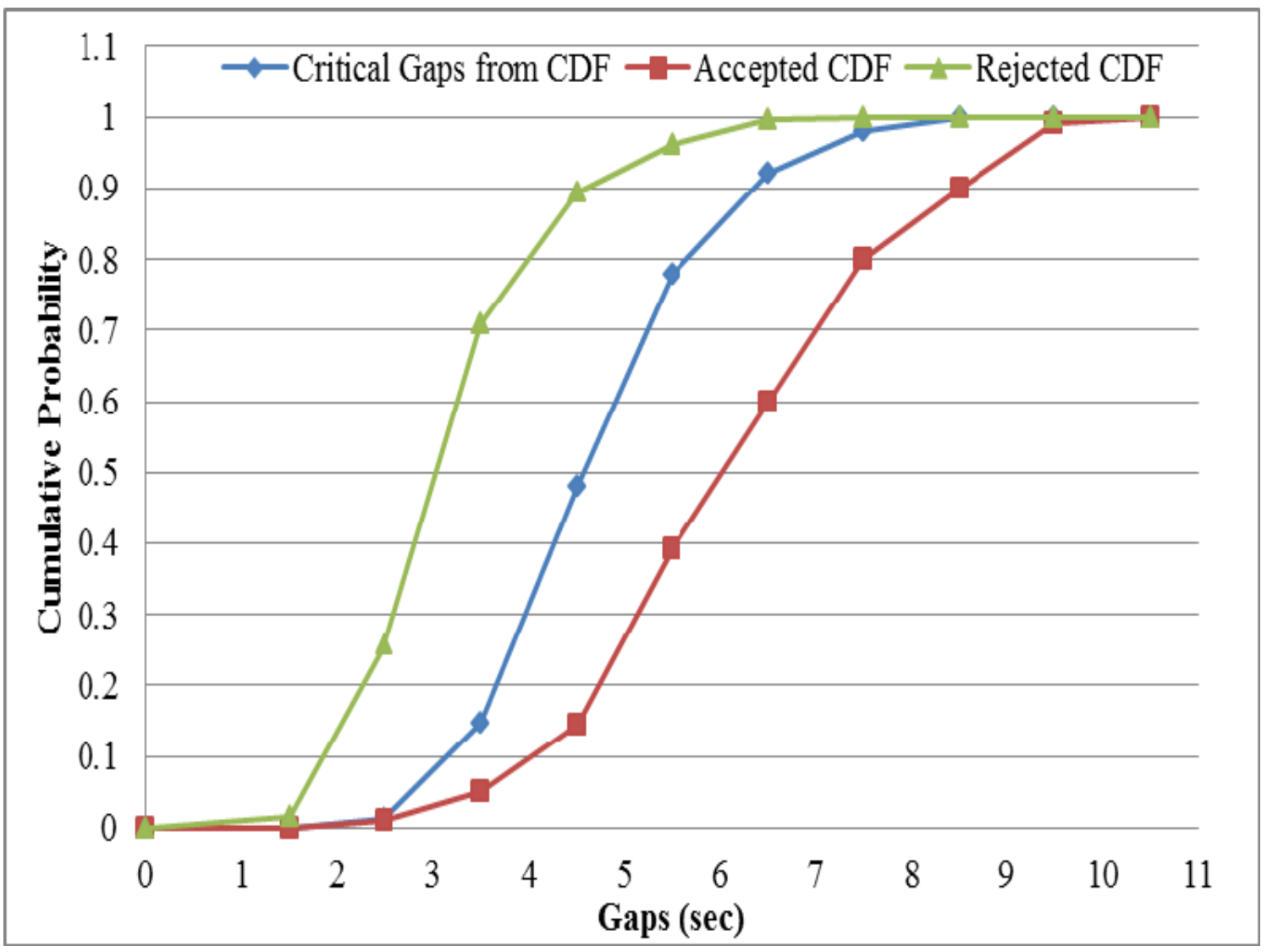

Fig. 3. CDFs for accepted gaps, rejected gaps and crtical gaps

\section{Headway Distribution Type Analysis}


6 Ren, L. and Qu, X.

As mentioned in introductory section, this study intends to analyse the distribution type of headways following. To this end, an engineering grogram, BestFit, is used to compare the histogram of headway samples and the probability of density function (PDF) of the exponential distribution. An example is illustrated in Fig. 4 as follows.

We then apply a Kolmogorov-Smirnov test (K-S test) to check whether headway samples follow an exponential distribution. The K-S test is a non-parametric test for the equality of continuous, one-dimensional probability distributions that can be used to compare a sample with a reference probability distribution (Jin et al., 2011; Meng and $\mathrm{Qu}, 2012$ ). A result of $\mathrm{K}-\mathrm{S}$ test for the example is shown in Table 1 as follows.
As can be seen in Table 1, the K-S statistic is greater than the criterion. In other words, the collected headways do not follow an exponential distribution. We then analyse headway distribution type of all nine roundabouts using the BestFit and the K-S test. Results are shown in Table 2 as follows.

According to results from the BestFit, only 3 headway samples follow exponential distributions. The majority of headway samples follow an inverse Gaussian distribution. In other words, inverse Gaussian distribution could be the best fitted distribution type of circulating headways following. The assumption of HCM 2000 model is not valid.

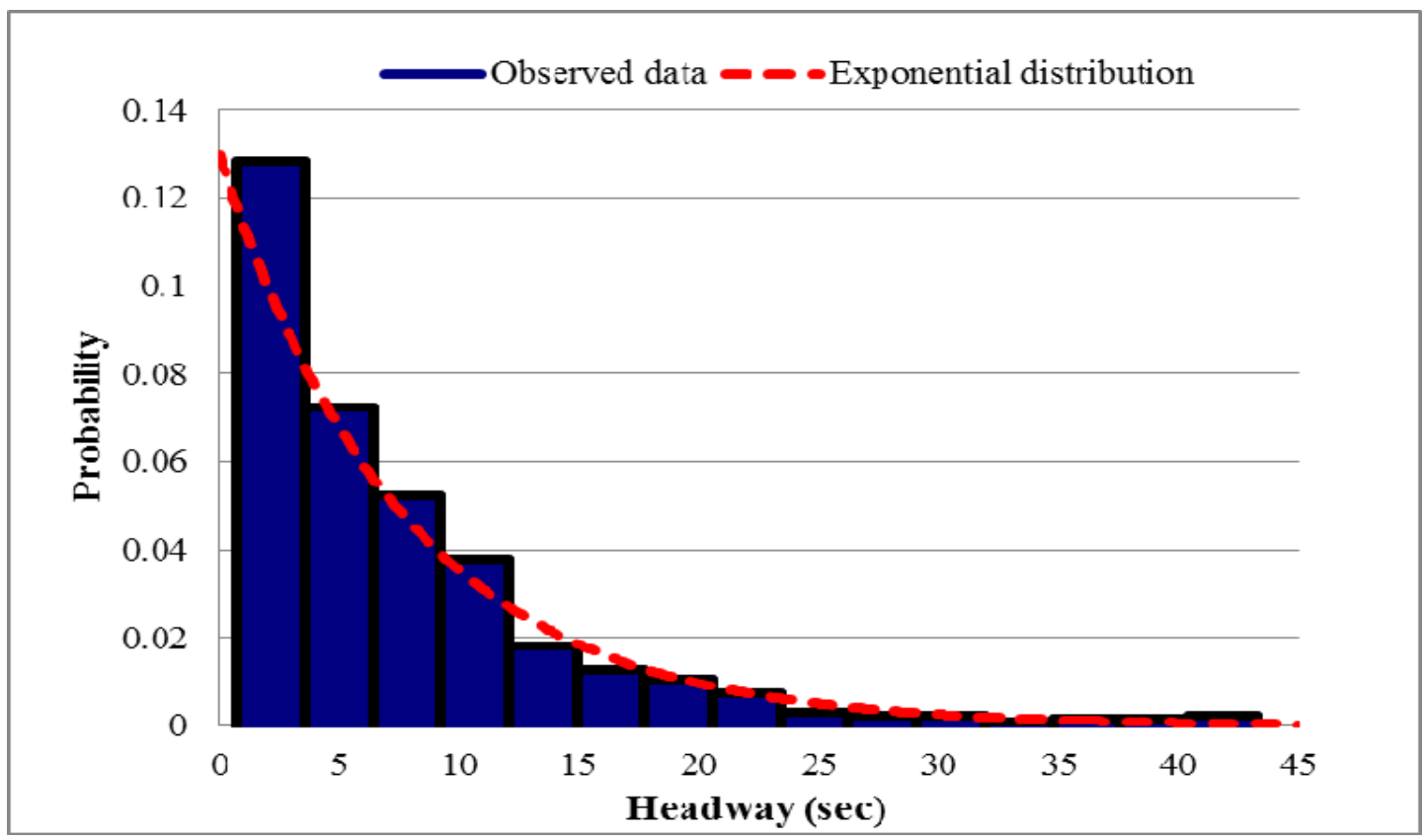

Fig. 4. Distribution comparison for headways

Table 1. K-S test for observed headways

\section{K-S Test}

\section{K-S statistic}

0.1104
Criterion

0.0704

Notes: Criterion is calculated by equation: $1.36 / \sqrt{N}$, where $N$ is number of headways (373).a

K-S statistic comes from the BestFit.

A sample suits to a reference probability distribution when K-S statistic is less than criterion.

Table 2. K-S test for nine observed roundabouts 


\begin{tabular}{cccccc}
\hline Roundabout & \multirow{2}{*}{$\begin{array}{c}\text { No. of } \\
\text { headways }\end{array}$} & Criterion & \multicolumn{3}{c}{ K-S statistic (Distribution types) } \\
\cline { 4 - 6 } & 109 & 0.1303 & 0.2141 & $0.0849^{*}$ & 0.2572 \\
\hline 1 & 99 & 0.1367 & 0.1610 & $0.0896^{*}$ & $0.0979^{*}$ \\
3 & 130 & 0.1193 & 0.3360 & $0.1029^{*}$ & 0.1365 \\
4 & 161 & 0.1072 & 0.3463 & $0.1055^{*}$ & 0.1275 \\
5 & 373 & 0.0704 & 0.1104 & $0.0528^{*}$ & $0.0551^{*}$ \\
6 & 189 & 0.0989 & $0.0682^{*}$ & $0.0764^{*}$ & 0.1800 \\
7 & 229 & 0.0899 & $0.0683^{*}$ & $0.0895^{*}$ & $0.0837^{*}$ \\
8 & 156 & 0.1089 & 0.1390 & 0.1210 & $0.1003^{*}$ \\
9 & 134 & 0.1175 & $0.0737^{*}$ & $0.0787^{*}$ & $0.0802^{*}$ \\
\hline Notes: “*” shows the acceptable distribution types. & & & & Inverse Gaussian & Lognormal \\
\hline
\end{tabular}

Notes: “*” shows the acceptable distribution types.

\section{Model Improvement}

As mentioned in the previous section, in most cases, the circulating headways do not follow exponential distributions. However, the HCM 2000 model provides an analytical solution to estimate roundabout entry capacity under an exponentially distributed assumption. In this study, we thus propose a simulation framework to estimate the entry capacities by taking into account the actual headway distributions.

\subsection{Simulation model}

In this study, a simulation model is developed based on gap acceptance theory. According to drivers' decision making process, the number of vehicles being able to enter a roundabout could be formulated by

$$
N=\left\{\begin{array}{l}
0, \text { if } T<\tau_{c} \\
i, \text { if } \tau_{c}+(i-1) \tau_{f} \leq T<\tau_{c}+i \tau_{f}
\end{array}\right.
$$

where $T$ is a time gap (headway) within circulating stream. Based on our field survey, various lengths of circulating headways are recorded for each roundabout. According to their corresponding calibrated critical gaps and follow-up times, the entry capacities for each roundabout can be estimated by summing numbers of vehicles being able to enter all headways in an hour. An example of the simulation is shown in Table 3. In the example, the calibrated critical gap and follow-up time are $4.61 \mathrm{sec}$ and $2.39 \mathrm{sec}$, respectively.

Similarly, the entry capacities for the other eight roundabouts are estimated, ranging from 514 to 1248 veh/hr. 
Table 3. An example of the simulation

\begin{tabular}{ccccc}
\hline $\begin{array}{c}\text { Cumulative time } \\
(\mathrm{sec})\end{array}$ & Headways, $T$ (sec) & $\begin{array}{c}\text { Simulated No. of } \\
\text { vehicles entering, } N\end{array}$ & $\begin{array}{c}\text { No. of headways, } n \\
\text { Simulated Capacity } \\
\text { (veh/hr) }\end{array}$ \\
\hline 0 & 0 & 0 & 0 & 1248 \\
23.273 & 23.273 & 8 & 1 & 2 \\
58.363 & 35.09 & 13 & 4 \\
59.937 & 1.574 & 2 & 5 \\
68.212 & 8.275 & 0 & 6 \\
71.475 & 3.263 & 1 & 7 \\
78.018 & 6.543 & 5 & 8 \\
92.302 & 14.284 & 5 & 9 \\
108.758 & 16.456 & 14 & 10 \\
146.738 & 37.98 & 4 & 11 \\
158.907 & 12.169 & 17 & $\ldots$ \\
202.453 & 43.546 & $\ldots$ & 257 \\
$\ldots$ & $\ldots$ & 4 & 258 \\
3596.479 & 12.458 & 0 &
\end{tabular}

Notes: Headway $=$ cumulative $_{\text {time }}-$ cumulative time $_{n-1}, \forall n \in(1,258)$

Conflicting flow, $v_{c}=$ No. of headways (258 veh $/ \mathrm{hr}$ )

Simulated capacity $=\sum_{n=1}^{n=258} N$

\section{A Comparison Study}

To modify the HCM 2000 model, we establish a linear function as a coefficient based on a regression analysis. In this study, all data for the regression analysis, including critical gaps, follow-up times and conflicting flows, are collected from nine observed roundabouts. For establishing the linear function, the following procedure is recommended:

1. Calibrate conflicting flow for one roundabout using the introduced simulated method in Table 3.

2. Based on its calibrated critical gap and follow-up time and conflicting flow, calculate entry capacity according to the HCM 2000 model using Eqn. (1).

3. Estimate entry capacity according to the simulation in Table 3.

4. Calculate a capacity ratio of the simulation to the HCM 2000 model.

5. Repeat step 1 to 4 and calculate capacity ratios for all nine observed roundabouts. Capacity ratios are shown in Appendix A.

6. According to nine capacity ratios, establish a linear function which is shown in Fig. 5.
As can be seen in Fig. 5, a linear trendline is found to show the relationship between the capacity ratio of the simulation to the HCM 2000 model and conflicting flow. The linear trendline represents a function to modify the HCM 2000 model as follows:

Calibrated ratio $=-0.0004 v_{c}+1.1065$

Additionally, the HCM 2000 model can be then modified as follows:

$C_{m}=\left(-0.0004 v_{c}+1.1065\right) \times C_{2000}$

where $C_{m}$ is the entry capacity from the modified HCM 2000 model.

In this study, we thus validate the modified HCM 2000 model. As can be seen in Appendix A, the modified HCM 2000 model provides a smaller value of relative error (0.92\%) and RMSD (12.79) than the HCM 2000 model (4.66\% and 48.17). Accordingly, the modified HCM 2000 model is proven outperform the HCM 2000 model. This finding successfully validates the feasibility of the modified HCM 2000 model. 


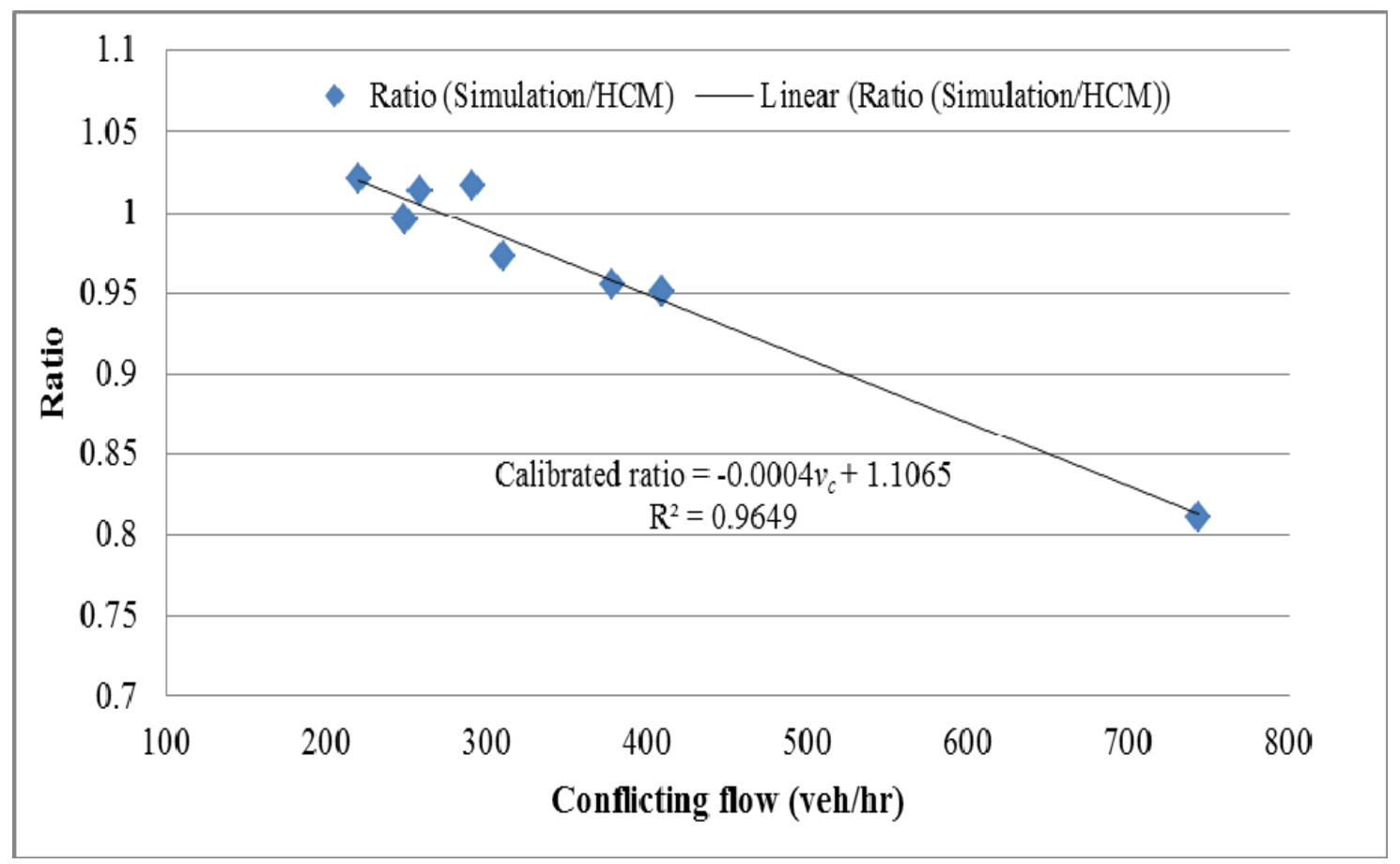

Fig. 5. Trendline of capacity ratio

\section{Conclusion}

The HCM 2000 model estimates roundabout entry capacity under an assumption of circulating headways following an exponential distribution. However, some studies indicated that the HCM 2000 model could over- or under-estimate entry capacity. This situation might be attributed to an unfit assumption of headway distribution type. Therefore, this study begins with analysis of headway distributions based on field survey. This study firstly indicates that the inverse Gaussian distribution is the best fitted distribution type of headway samples. According to this finding, we thus intend to adjust the HCM 2000 model. To this end, we propose a simulation based approach to estimate entry capacity of single-lane roundabouts. A linear relationship is established to represent the relationship between a capacity ratio of the simulation-based approach to the HCM 2000 model and conflicting flow. The linear function can be considered as a coefficient of the HCM 2000 model. It is believed that the modified HCM 2000 model outperforms the HCM 2000 model.

\section{Reference}

Al-Ghandour, M., Rasdorf, W., Williams, B., and Schroeder, B., (2011). Analysis of Single-Lane Roundabout Slip Lanes Using SIDRA. Transportation and Development Institute Congress 2011, 1235-1244.

Bared, J. G. and Afshar, A. M., (2009). Using Simulation to Plan Capacity Models by Lane for Two- and Three-Lane Roundabouts. In Transportation Research Record: Journal of the Transportation Research Board, No. 2096, Transportation Research Board of the National Academies, Washington, D. C., 2009, pp. 8-15.

Bie, J., Lo, H. K., and Wong, S., (2012). Capacity Evaluation of Multi-lane Traffic Roundabouts.
Journal of Advanced Transportation, Vol. 44, 2012, pp. 245-255.

Cowan, R. C., (1997). Useful Headway Models. Transportation Research, Vol. 9, 1997, pp. 371-375.

Dahl, J. and Lee, C., (2012). Empirical Estimation of Capacity for Roundabouts Using Adjusted GapAcceptance Parameters for Trucks. In Transportation Research Record: Journal of the Transportation Research Board, No. 2312, Transportation Research Board of the National Academies, Washington, D. C., 2012, pp. 34-45.

Diah, J. M., Rahman, M. Y. A., Adnan, M. A., and Khoo, H. L., (2011). Modeling the Relationship between Geometric Design and Weaving Section Flow Process of Conventional Roundabouts. ASCE Journal of Transportation Engineering, Vol. 137, 2011, pp. 980-986.

Flannery, A., (2001). Geometric Design and Safety Aspects of Roundabouts. In Transportation Research Record: Journal of the Transportation Research Board, No. 1751, Transportation Research Board of the National Academies, Washington, D. C., 2001, pp. 76-81.

Flannery, A. and Datta, T. K., (1997). Operational Performance Measures of American Roundabouts. Presented at the $76^{\text {th }}$ Annual Meeting of the Transportation Research Board, Washinton, D. C., 1997.

Fortuijn, L. G., (2009). Turbo Roundabouts Estimation of Capacity. In Transportation Research Record: Journal of the Transportation Research Board, No. 2130, Transportation Research Board of the National Academies, Washington, D. C., 2009, pp. 83-92.

Harders, J., (1968). Die Leistungsfähigkeit Nicht Signalgeregelter Städtischer Verkehrsknoten (Capacity of Unsignalized Urban Intersections). Straßenbau und Straßenverkehrstechnik, Heft 76. 
Hrsg: Bundesminister für Verkehr, Abt. Straßenbau, Bonn, 1968.

Hellinga, B. and Sindi, A., (2012). Analytical Method for Estimating Delays to Vehicles Traversing SingleLane Roundabouts as a Function of Vehicle and Pedestrian Volumes. In Transportation Research Record: Journal of the Transportation Research Board, No. 2912, Transportation Research Board of the National Academies, Washington, D. C., 2012, pp. 56-66.

Isebrands, H. and Hallmark, S., (2012). Statistical Analysis and Development of Crash Prediction Model for Roundabouts on High-Speed Rural Roadways. In Transportation Research Record: Journal of the Transportation Research Board, No. 2312, Transportation Research Board of the National Academies, Washington, D. C., 2012, pp. 3-13.

Jin, S., Qu, X. B., and Wang, S. A., (2011). Assessment of Expressway Traffic Safety Using Gaussian Mixture Model Based on Time to Collision. International Journal of Computational Intelligence Systems, Vol. 4, 2011, pp. 1122-1130.

Kittleson and Associates. Modern Roundabouts., (2011). The Web Site: http://roundabouts.kittelson.com/Roundabouts Accessed on August 2011.

Ko, C. H., (2012). Multidisplinary Engineering, Project, and Production Management. Journal of Engineering, Project, and Production, 2(1), 1.

Lee, C., (2015). Developing Passenger-Car Equivalents for Heavy Vehicles in Entry Flow at Roundabouts. ASCE Journal of Transportation Engineering, 141(8), 04015013.

Lochrane, T., Kronprasert, N., Bared, J., Dailey, D., and Zhang, W., (2014). Determination of MiniRoundabout Capacity in the United States. ASCE Journal of Transportation Engineering, 140(10), 04014051.

Mauro, R. and Branco, F., (2010). Comparative Analysis of Compact Multilane Roundabouts and TurboRoundabouts. ASCE Journal of Transportation Engineering, 136(4), 316-322.

Meng, Q. and Qu, X. B., (2012). Estimation of Rear-End Vehicle Crash Frequencies in Urban Road Tunnels. Accident Analysis and Prevention, Vol. 48, 2012, pp. 254-263.

Mereszczak, Y., Dixon, M., Kyte, M., Rodegerdts, L., and Blogg, L., (1998). Including Exiting Vehicles in Capacity Estimation at Single-lane U.S. Roundabouts. In Transportation Research Record: Journal of the Transportation Research Board, No. 1988, Transportation Research Board of the National Academies, Washington, D. C., 2006, pp. 23-30.

Munawar, A. and Haryanto, S., (2010). Optimizing Signalized Roundabout by Computer Simulation (Case Study: Pelem Gurih Roundabout, Yogyakarta). Traffic and Transportation Studies 2010, 357-364.

Pinna, F. and Piras, C., (2011). Non-Standard Roundabouts: Analysis of Problems. Transportation and Development Institute Congress 2011, 12551265.

Polus, A., Lazar, S. S., and Livneh, M., (2003). Critical Gap as a Function of Waiting Time in Determining Roundabout Capacity. ASCE Journal of Transportation Engineering, Vol. 129, 2003, pp. 504-509.
Qiu, T. Z. and Yin, D., (2011). Comparison of Macroscopic and Microscopic Simulation Models in Modern Roundabout Analysis. In Transportation Research Record: Journal of the Transportation Research Board, No. 2265, Transportation Research Board of the National Academies, Washington, D. C., 2011, pp. 244-252.

Qu, X., Ren, L., Wang, S., and Oh, E., (2014). Estimation of entry capacity for single-lane modern roundabouts: A case study in Queensland, Australia. Journal of Transportation Engineering. 140(7), 05014002.

Raff, M. S. and Hart, J. W., (1950). A Volume Warrant for Urban Stop Sign. Traffic Engineering and Control, Vol. 5, 1950, pp. 255-258.

Sarker, B. and Baylot, E., (2012). Throughput Capacity Estimation for Convoy Movement in Linked Roads. ASCE Journal of Transportation Engineering, 138(9), 1133-1142.

Siegloch, W., (1973). Die Leistungsermittlung a Knotenpunkten Ohne Lichtsignalsteuerung (Capacity Estimation at Unsignalized Intersections). Straßenbau und Straßenverkehrstechnik, Heft 154. Hrsg.: Bundesminister für Verkehr, Abt. Straßenbau, Bonn, 1973.

Rodegerdts, L., Bansen, J., Tiesler, C., Knudsen, J., Myers, E., Johnson, M., Moule, M., Persaud, B., Lyon, C., Hallmark, S., Isebrands, H., Crown, R. B., Guichet, B., and O’Brien, A., (2010). Roundabouts: An Informational Guide Second Edition. NCHRP Report 672, Transportation Research Board.

Transportation Research Board (TRB). Highway Capacity Manual 2000.

Troutbeck, R., (1992). Estimating the Critical Acceptance Gap from Traffic Movements. Research Report, Vol. 92, 1992.

Turner, S., Wood, G., Hughes, T., and Singh, T., (2011). Safety Performance Functions for Bicycle Crashes in New Zealand and Australia. In Transportation Research Record: Journal of the Transportation Research Board, No. 2236, Transportation Research Board of the National Academies, Washington, D. C., 2011, pp. 66-73.

Wei, T., Grenard, J. L., and Shah, H. R., (2011). Developing Capacity Models for Local Roundabouts Streamlined Process. In Transportation Research Record: Journal of the Transportation Research Board, No. 2257, Transportation Research Board of the National Academies, Washington, D. C., 2011, pp. 1-9.

Wei, T. and Grenard, J. L., (2012). Calibration and Validation of Highway Capacity Manual 2010 Capacity Model for Single-Lane Roundabouts. In Transportation Research Record: Journal of the Transportation Research Board, No. 2286, Transportation Research Board of the National Academies, Washington, D. C., 2012, pp. 150-110.

Wong, S. C., (1996). On the Reserve Capacities of Priority Junctions and Roundabouts. Transportation Research Part B, Vol. 30, 1996, pp. 441-453.

Wu, N., (2012). Equilibrium of Probabilities of Estimating Distribution Function of Critical Gaps at Unsignalized Intersections. In Transportation Research Record: Journal of Transportation Research Board, No. 2286, Transportation Research Board of the National Academies, Washington, D. C., 2012, pp. 49-55. 
Yap, Y. M., Gibson, H., and J. Waterson, B., (2015). Models of Roundabout Lane Capacity. ASCE Journal of Transportation Engineering, 141(7), 04015007.

Yousif, S., Alterawi, M., and Henson, R., (2013). Effect of Road Narrowing on Junction Capacity Using Microsimulation. ASCE Journal of Transportation Engineering, 139(6), 574-584.

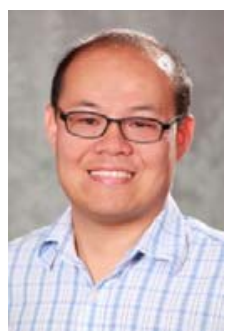

Dr. Xiaobo Qu is a Senior Lecturer with the Griffith School of Engineering, Griffith University, Gold Coast, Australia. He received his Bachelor of Engineering in transport engineering from Jilin University, Master of Science in industrial engineering from Tsinghua University, and $\mathrm{PhD}$ from National University of Singapore. His research is focused on traffic flow theory and its applications. He also occasionally works on public transport, maritime transportation, and infrastructure resilience.

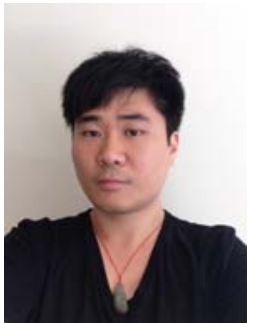

safety analysis.
Mr. Liang Ren received the Bachelor's degree in Civil Engineering from Griffith University, Gold Coast, Australia in 2011. He is currently a Ph.D. Student in the School of Engineering, Griffith University. His current research interests include roundabout capacity modeling, performance evaluation and 
12 Ren, L. and Qu, X.

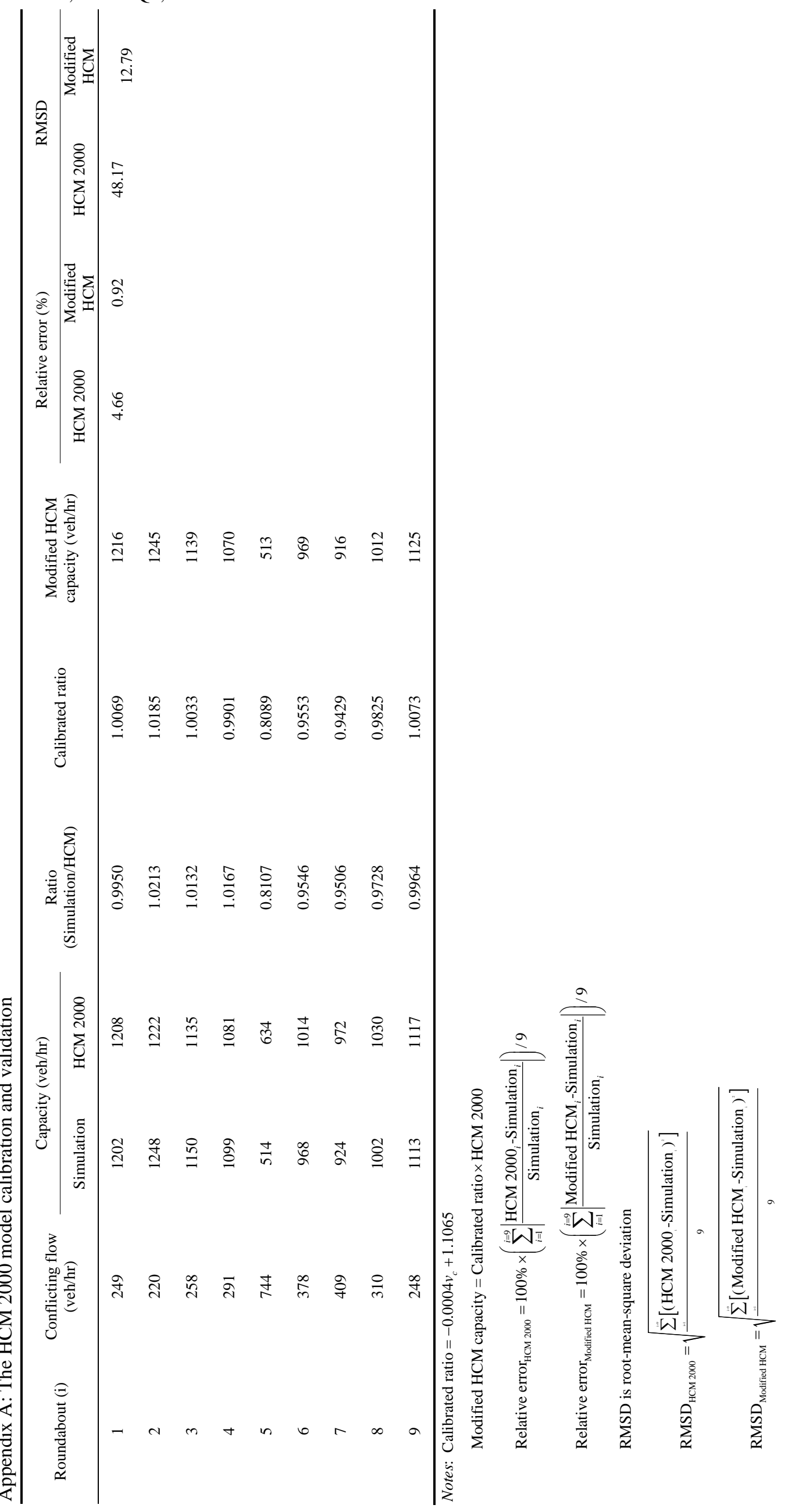

Journal of Engineering, Project, and Production Management, 2016, 6(1), 2-12 